\title{
Congenital vertical talus
}

INSERM

\section{Source}

INSERM. (1999). Orphanet: an online rare disease and orphan drug data base. Congenital vertical talus. ORPHA:178382

Isolated congenital vertical talus (CVT) is a rare pedal deformity recognizable at birth by a dislocation of the talonavicular joint, resulting in a characteristic radiographic near-vertical orientation of the talus. 